\title{
Rational action without knowledge (and vice versa)
}

\author{
Jie Gao ${ }^{1}$
}

Received: 3 November 2013 / Accepted: 18 January 2016 / Published online: 8 February 2016

(C) The Author(s) 2016. This article is published with open access at Springerlink.com

\begin{abstract}
It has been argued recently that knowledge is the norm of practical reasoning. This norm can be formulated as a bi-conditional: it is appropriate to treat $p$ as a reason for acting if and only if you know that $p$. Other proposals replace knowledge with warranted or justified belief. This paper gives counter-examples of both directions of any such bi-conditional. To the left-to-right direction: scientists can appropriately treat as reasons for action propositions of a theory they believe to be false but good approximations to the truth for present purposes. Cases based on a variant of Pascal's Wager and actions performed by a skeptic also illustrate the point. To the right-to-left direction: in certain circumstances, it can be unreasonable for a scientist to reason from propositions of a theory she knows to be true.
\end{abstract}

Keywords Action P Practical rationality $\cdot$ Knowledge $\cdot$ Belief $\cdot$ Acceptance

\section{The epistemic norms of practical reasoning}

Intuitively, before the result of a lottery is announced, it seems inappropriate for me to sell my lottery ticket for a penny on the basis that I will lose, since I do not know that the ticket is a loser. In the same spirit, I can be criticized for not buying insurance in a situation in which I do not know that I will not get sick. On the other hand, if I know that my door is locked, it seems that there is nothing wrong for me not to come back and check whether it is locked. On the basis of similar intuitions about ordinary appraisals and criticisms of action, some philosophers have argued that practical reasoning is

\footnotetext{
Jie Gao

philobaikal@gmail.com

1 School of Philosophy, Psychology and Language Sciences, University of Edinburgh, 3 Charles Street, Edinburgh EH8 9AD, UK
} 
governed by a knowledge norm. ${ }^{1}$ Consider a specific version of the norm, suggested by Hawthorne and Stanley (2008):

\section{Reason-Knowledge Principle (RKP)}

Where one's choice is $p$-dependent, it is appropriate to treat the proposition that $p$ as a reason for acting iff you know that $p(578){ }^{2}$

RKP can be split into the two following conditionals:

NEC: where one's choice is $p$-dependent, if it is appropriate to treat $p$ as a reason for acting, then $S$ knows that $p$.

SUFF: where one's choice is $p$-dependent, if $S$ knows that $p$, then it is appropriate to treat $p$ as a reason for acting.

The claim that knowledge is the norm of practical reasoning has been followed by a wave of criticism. It has been remarked that data about our ordinary use of "know" only provides a very fragile basis for concluding that practical reasoning is governed by such a norm, since sometimes we use "knowing" in a loose sense, meaning "being certain" or "truly believing" (Gerken 2011, 2015; Littlejohn 2009). It has been argued that the same alleged data used to motivate the knowledge norm can be explained assuming other epistemic norms as well (Gerken 2011, 2015; Littlejohn 2009; Neta 2009). Moreover, in some cases the knowledge norm seems to fail to deliver the right verdict. For example, it seems that the knowledge norm cannot accommodate intuitions in Gettier-style cases in which the subject is blameless in treating a justified true belief that $p$ as a reason for acting, even in the absence of knowledge (Brown 2008a, b; Gerken 2011; Littlejohn 2009).

Given these difficulties, some philosophers have opted for other weaker principles that not only are compatible with the original data motivating the knowledge norm, but

1 For example, Hawthorne claims that "if $p$ is practically relevant, it is acceptable to use the premise that $p$ in one's practical reasoning if one knows that $p$ and (at least in many cases) unacceptable to use the premise that $p$ in one's practical reasoning if one doesn't know it" (2004, p. 30). Stanley (2005) holds that one should act on $p$ only if one knows that $p$ (9). Fantl and McGrath (2007) argue that $S$ knows that $p$ only if $S$ is rational to act as if $p(559)$.

2 Three remarks about RKP are in order here: First, according to Hawthorne and Stanley, a choice between options $\mathrm{x}_{1} \ldots \mathrm{x}_{\mathrm{n}}$ is $p$-dependent iff the most preferable of $\mathrm{x}_{1} \ldots \mathrm{x}_{\mathrm{n}}$ conditional on the proposition that $p$ is not the same as the most preferable of $\mathrm{x}_{1} \ldots \mathrm{x}_{\mathrm{n}}$ conditional on the proposition that not- $p$ (Ibid., 578). Such a condition is needed for there are many cases where $p$ is completely irrelevant to the issue at hand, so it seems odd to say that it is appropriate to treat the proposition that $p$ as a reason for acting, even if one knows that $p$. Second, the notion of appropriateness in RKP is supposed to be understood as rational permissibility, rather than in terms of obligation. As Hawthorne and Stanley (2008) point out, "it would be overly demanding to require someone to treat all of their relevant knowledge as reasons for each action undertaken". Third, there are two readings of "treating $p$ as a reason for action" but only one of them is compatible with the intuition that RKP is supposed to capture. One is to take "treating $p$ as a reason for action" as "using $p$ as a premise in practical reasoning". This interpretation is in accordance with the formulation endorsed by Hawthorne (2004) and is the most intuitive understanding. According to another stronger reading, nothing less than knowledge can be considered as a reason. This view implies that if $p$ is $S$ 's reason for acting, $S$ knows that $p$. However, if treating $p$ as a reason for acting already entails that $p$ is known, $S$ 's reasoning cannot be assessed normatively according to whether $S$ knows that $p$. Therefore this notion cannot be the one used in RKP. Thus, those who may find the notion "treating $p$ as a reason for acting" vague can safely substitute the notion with "using $p$ as a premise in practical reasoning". Neta (2009) points out that "treating $p$ as a reason for acting" differs from "using $p$ as a premise in practical reasoning" in some respects, but the difference is irrelevant for the discussion here. 
also provide good explanations for the cases in which the knowledge norm delivers the wrong verdict. For instance, Littlejohn (2009, 2012) and Fantl and McGrath (2002) argue that the norm of practical reasoning is justified belief, ${ }^{3}$ Gerken (2011) suggests that it is belief that $p$ warranted to a degree that is adequate relative to the deliberative context, and Neta (2009) argues that it is justified belief that one knows that $p$. In spite of the divergence among these proposals, all of them hold that the norm of practical reasoning is belief plus some other property. Let's call these epistemic norms of practical reasoning doxastic norms. As in the case of the knowledge norm, these norms can come in necessity and sufficiency versions depending on whether the relevant doxastic property is necessary or sufficient for appropriateness.

Against all these views, I doubt that there is an epistemic norm concerning the appropriateness conditions for treating a proposition as a reason for acting. ${ }^{4}$ In this paper, I provide two counterexamples to the knowledge norm. I show cases in which it is appropriate for a subject to treat $p$ as a reason for action even if the subject does not know that $p$. These are cases in which actions are grounded in acceptance and performed by a skeptic. These cases show that knowledge is not necessary for appropriately treating a proposition as a reason for action. Furthermore, I argue that, under a certain interpretation of epistemic norms, the first case constitutes a counterexample also to SUFF, according to which knowing that $p$ is epistemically sufficient for appropriately treating $p$ as a reason for acting. In addition, these cases are also good counterexamples against the alternative doxastic norms mentioned above including belief as a requisite, since in both counterexamples the subject does not even hold a belief about the relevant proposition. My final conclusion is that, even if knowledge, as well as justified belief, warranted belief, and similar doxastic attitudes, play an important role in the rationalization of many our actions, these attitudes are not necessary for appropriately treating a proposition as a reason for action. Moreover, according to a specific understanding of epistemic norms, they are even not sufficient. In many circumstances, different mental attitudes, such as acceptance, provide us with appropriate bases for action. Such cases show that there is no epistemic norm governing practical reasoning. 5

Before proceeding further, three clarifications are in order. ${ }^{6}$ First, the upshot of my arguments is not that there is no norm at all governing practical reasoning. My arguments are consistent, for example, with the existence of other non-epistemic norms governing practical reasoning. The aim of my arguments is rather to provide counterexamples to the claim that practical reasoning is governed by an epistemic norm-a norm whose satisfaction condition is constituted by an epistemic notion such as (jus-

\footnotetext{
3 Littlejohn has recently abandoned this view and now defends a knowledge norm. See Littlejohn (2013) for his recent view.

4 Brown (2008a, b) questions the existence of such norms as well.

5 At least if such a norm is conceived as an exceptionless principle valid for every possible premise of a practical reasoning. This is precisely how philosophers engaged in this debate conceive such a norm. The arguments in this article are compatible with epistemic norms ranging on some proper subset of such premises.

6 I would like to thank an anonymous referee for this journal for pointing out to me these important clarifications.
} 
tified or warranted) belief or knowledge. This is precisely the crux of the debate on epistemic norms of practical reasoning introduced above. ${ }^{7}$

Second, my examples aim to show that there are cases in practical reasoning in which it is appropriate to reason from premises that are not known or believed. This is compatible with the claim that other premises used in the same reasoning are known or believed. In all my examples below, the subject is rational in using premises she doesn't know or believe in reasoning in which other premises are known. This is sufficient to show that there are no universally valid epistemic norms like RKP. ${ }^{8}$

The third clarification concerns the specific sense in which these norms for practical reasoning count as epistemic. According to one obvious understanding, these norms are epistemic in virtue of the fact that they demand that some epistemic condition with respect to $p$ be satisfied for it to be appropriate to use $p$ as a premise in practical reasoning. According to another understanding, such norms are epistemic because they assess whether it is epistemically appropriate to use $p$ as a premise in practical reasoning — where 'epistemically' characterizes the type of appropriateness and differentiates it from other types of appropriateness: prudential, rational, moral, aesthetic, etc. ${ }^{9}$ While there is agreement on the fact that such norms are epistemic in the former sense, there is no consensus on whether they are also epistemic in the latter sense. Philosophers such as Fantl and McGrath (2009) and Gerken (2011) answer affirmatively to this question, whereas others, such as Brown (2008a, b), remain neutral on this issue, characterizing epistemic norms exclusively in the former sense. Still others, such as Hawthorne (2004) and Hawthorne and Stanley (2008), think that epistemic norms of practical reasoning are standards of rational appropriateness broadly conceived, not strictly epistemic. While my objections to NEC will be effective against both understandings of epistemic norms, my objection to SUFF will be specifically directed to views which do not conceive epistemic norms as standards of strictly epistemic appropriateness, such as the views of Hawthorne and Stanley.

\footnotetext{
7 For example, Gerken specifies that the type of norms relevant to the present debate only speak to the epistemic conditions under which $p$ may serve as a premise in practical deliberation or as a reason for action. According to Gerken, authors engaged in this debate are interested in the distinctively epistemic conditions on rational use of $p$ (Gerken 2011, p. 531 and fn. 3). For similar remarks see, for example Brown (2012, p. 125). I note also that, though the upshot of my argument is negative, one could eventually draw positive conclusions from it about which non-epistemic conditions can rationalize a practical reasoning.

8 It is worth mentioning here that the specific focus of this paper is on epistemic norms of action. The paper does not address further issues concerning norms of belief. See Benton (2014, Sect. 3) for an overview of recent discussions on norms of belief and for relevant references. The aim of the present paper is not to demote knowledge (or other epistemic attitudes), but rather simply to argue - against (RKP) and other epistemic norms of action-that believing (and thus knowing) that $p$ is neither necessary, nor sufficient to reasonably take $p$ as a reason for action.

9 In this sense, epistemic norms would depend on a genuinely epistemic normative source. For a discussion of different sources of normativity see, for example, Broome (2013, pp. 26-27 and Ch. 7).
} 


\section{Counterexamples to epistemic norms of practical reasoning}

\subsection{Acceptance and practical reasoning}

For a long time philosophers of mind used to explain action within a belief-desire framework. According to this model, when we act we seek to realize our intentions and satisfy our desires in the light of what we believe. Similarly, in our practical reasoning we would reason from desires, beliefs and intentions to action. However, this philosophical orthodoxy has been called into question: some philosophers have argued that other attitudes can motivate action and figure as premises in practical reasoning. A mental attitude often discussed in the literature that plays an important role in our practical reasoning is acceptance. In what follows, I will illustrate the close tie between acceptance and practical reasoning and how it poses a serious challenge to the knowledge norm and other doxastic norms of practical reasoning.

Before discussing the relation between acceptance and practical reasoning, it is necessary to clarify the notion of acceptance relevant for the present discussion and how it differs from that of belief. According to some stipulative notions of acceptance, belief is a kind of acceptance. For example, David Velleman equates accepting that $p$ with regarding $p$ as true. Since believing necessarily involves regarding a proposition as true, it is a kind of acceptance. For Velleman, supposing, assuming, and propositional imagining are other kinds of acceptance (Velleman 2000, pp. 249-250). Similarly, for Crispin Wright, there is acceptance in all cases where the agent acts in a way as if she believes that proposition. Also according to this notion, belief is a type of acceptance. Other attitudes that fall into the category of acceptance include acting on the assumption that $p$, taking for granted that $p$ and trusting that $p$ for reasons that do not bear on considerations regarding the truth of $p$ (Wright 2004, pp. 177-180).

On the contrary, according to a narrower and more natural reading of acceptance that I use here, acceptance and belief are two different kinds of mental attitude. Many have argued that acceptance in this narrower sense is an attitude widely adopted in our ordinary, religious, scientific and technological practices. ${ }^{10}$ Here is an example adapted from Michael Bratman (1992, p. 5). I am in Rome on a June day and I am planning my journey to visit the city. I do not actually have a belief about whether it will rain or not, nor do I have sufficient reason to believe that it will not rain-e.g., the weather forecast for that day is not available and according to the records there have been some showers in June in past years. Nevertheless, in my present circumstances taking for granted that it will not rain simplifies my planning in a way that is useful. On the basis of that acceptance I decide to leave the umbrella at my hotel. Below I will consider other examples of acceptance.

\footnotetext{
10 For instance, Alston (1996), Audi (2008), Rey (2007), Sperber (1996) and Van Leeuwen (2014) all argue that religious attitudes are acceptance or acceptance-like rather than belief or belief-like. Cohen (1992), Maher (1990), Mosterín (2002), and Van Fraassen (1980) have argued that it is reasonable for scientists to merely accept the content of their scientific theories but not believe them. Bratman (1992) and Cohen (1989) discuss ordinary examples of acceptance such as the one considered immediately below.
} 
It has been argued that acceptance differs from belief in at least three respects. ${ }^{11}$ First, acceptance and belief differ from each other in terms of the requirements of rationality governing the two attitudes. Reasonable belief is peculiarly responsive to truth-conducive, epistemic factors; believing a proposition requires regarding it as true with the aim or commitment of getting its truth-value right. ${ }^{12}$ On the contrary, acceptance doesn't involve commitments to the truth of the accepted proposition. ${ }^{13}$ There are no rational requirements to accept a proposition only if it is true. Accepting a proposition only involves treating it as if it were true, regardless of whether it is true or not. ${ }^{14}$ This doesn't mean that acceptances are not the object of rationality requirements and are not liable to criticisms. Standards for rational acceptance concern non-epistemic factors, such as instrumental, ethical and prudential considerations. Acceptances are assessed according to whether it is useful or convenient for the agent to accept $p$ given her practical purposes, whether accepting $p$ maximizes one's expected utility, and so on. ${ }^{15}$

Second, while belief is context independent or context invariant, acceptance is context dependent. When we believe something, we regard it as true no matter what our practical situation. By contrast, what one accepts can vary from context to context depending on the particular practical demands of the situation. These demands can sometimes make it reasonable for an agent to accept a proposition in a given context,

11 Philosophers who have defended the distinction between belief and acceptance include Alston (1996), Audi (2008), Bratman (1992). Buckareff (2004), Dub (2015), Engel (1998), Mosterín (2002), Rey (1988), Stalnaker (1984), Tuomela (2000), Van Fraassen (1980), Velleman (2000). Other proposals in characterizing an acceptance-like mental state include de Sousa's 'assent' (1971), Dennett's 'opinion' (1978), Sperber's 'reflective belief' (1996,1997) and Frankish's 'superbelief' (2004). There are important differences between these authors in the ways they draw the distinction between belief and acceptance, but the three essential differences identified here are common to most of them.

12 For a defense of similar claims see for example, Velleman (2000), Wedgwood (2002, 2013), Shah (2003), Steglich-Petersen (2006), Engel (2013).

13 We use 'commitment' in at least two senses. On the one hand, commitment refers to an attitude of endorsement; on the other hand, it refers to a norm or a requirement. In what we may call the 'requirement' sense, a commitment is a requirement or a norm that an agent is committed to respect. Such a norm would take the following form: accept that $p$ only if $p$ (or only if there is evidence for $p$ ). This type of commitment is much discussed in the literature on the normativity of belief (cf. McHugh and Whiting 2014). There are no requirements of this sort on acceptance in the narrow sense relevant here: acceptance doesn't involve a commitment to endorse a proposition only if its content is true, as belief does. If acceptance involves some commitment to the truth, it is in a different sense, which we may call 'endorsement': this is an endorsement or intention that the agent deliberately takes toward a proposition, making as if that proposition were true for practical purposes.

14 For example, Vahid (2006, pp. 323-324) argues that while belief involves regarding $p$ as true for its own sake (or for the sake of getting its truth value right), other attitudes involve regarding $p$ as true for the sake of something else. For example, assuming involves regarding $p$ as true for the sake of argument (i.e. in order to see what it entails), and imagining involves regarding $p$ as true for motivational purposes. An analogous claim can be made for acceptance. In the sense used here, acceptance is regarding $p$ as true for the sake of practical purposes. In a similar vein, Cohen writes that " $[\mathrm{t}] \mathrm{o}$ accept that $p$ is to adopt the policy of taking the proposition that $p$ as a premise in appropriate circumstances" (1989, p. 374).

15 For similar characterizations of acceptance, see Bratman (1992) and Cohen (1989). My examples in the text will focus on a specific practical functional role of acceptance, that of helping us to make our practical reasoning more economical and faster in some circumstances, allowing us to avoid the use of more complex believed propositions. I just note here that there can be other practical purposes making rational the use of acceptances as premises in reasoning. See the quoted references for other examples. 
even though she would not reasonably accept the same proposition in another context. While in planning my journey for a visit to Rome I reasonably accept that it will not rain, if I were figuring out what odds I would put in a bet on the weather I would not rely on that acceptance (Bratman 1992, p. 5). Contextual dependence of acceptance explains why, while belief is subject to an ideal of agglomeration across contextsone should be able to or aim to integrate one's various beliefs into one consistent and coherent larger view - one may accept certain things which do not cohere with her other beliefs, for mere practical reasons present in a specific context.

Third, acceptance and belief differ from each other with respect to voluntary control. Normally, believing a proposition is an involuntary mental state. It is a disposition I find myself having, a product of my automatic cognitive mechanism. Furthermore, one cannot form or revise a belief at will regardless of the evidence (or at least not in normal circumstances). By contrast, accepting a proposition is, or is generated by, a mental act involving voluntarily taking on a positive attitude toward a proposition depending on practical considerations. ${ }^{16}$

By bearing this in mind, we can find a series of cases in which it is reasonable for the subject to accept that $p$ under practical pressure, and appropriate to treat $p$ as a reason for action, in spite of not having good reason to believe it (or even having good reasons to believe the contrary). All the situations in which it is rational to act on a proposition that is accepted but not believed constitute counterexamples to NEC and necessity versions of other doxastic norms.

A variant of Pascal's Wager provides us with a good example here. Considerations about how it might be beneficial to live as if God exists cannot ground beliefs about God's existence. Nonetheless, they are indeed good practical reasons for accepting that God exists. ${ }^{17}$ Suppose one rationally decides to wager for the existence of God purely on the basis of a calculation of expected utility. This person would thereby accept but not believe that God exists. She would then take the proposition that God exists as a premise in her practical reasoning and simply endorse the policies and assent (at least externally) to the doctrines of the Church. She doesn't need to make that calculation over and over again each time this proposition matters to her practical decisions; and

\footnotetext{
16 Mosterín (2002, pp. 317-319) makes a similar point in terms of the ways of processing information involved in forming belief and acceptance. He observes that belief is typically tied to unconscious processing of information whereas acceptance is generated by conscious, explicit, linguistically articulated decisiondriven processing of information. Dub (2015) has argued that delusions constitute pathological cases of acceptance that are formed involuntarily. If this is correct, acceptances are not always voluntarily formed and under the control of the will. Nonetheless, the possibility that acceptance can be controlled voluntarily still constitutes a genuine difference between acceptance and belief. My examples below will refer exclusively to voluntary cases of acceptance.

17 Notice here an important difference with respect to the original Pascal's Wager case. Pascal's God demands that we believe in him-mere acceptance is not sufficient. According to Pascal, the reason for going to church is to cause oneself to believe that God exists. In the present example I consider a case in which $S$ doesn't take God to ask him to believe in His existence. Instead, $S$ 's acceptance of God is merely motivated by how practically beneficial it would be to live as if God existed. Thanks to an anonymous referee for making this difference clear to me. It is also worth mentioning here that a rational agent convinced by this type of Pascalian-like reasoning should have some minimal degree of credence that God exists. This is because part of the Pascalian reasoning relies on attributing at least a small chance that God exists. This subjective chance allows accepting that God exists to maximize expected utility. This wouldn't be the case if the agent's credence that God exists were zero.
} 
she doesn't even need to treat the believed proposition 'if God exists and I don't behave in accordance with God's doctrines, then I will receive severe punishment after I die' as a reason for action every time she engages in a relevant practical reasoning. Rather, in many circumstances she will simply treat the accepted proposition that God exists as a reason for her action. For example, she may be motivated by this acceptance to spend more time in the church and follow the precepts of religion. ${ }^{18}$ Moreover, though she merely accepts that God exists, it seems that it is not inappropriate or irrational for her to treat that accepted proposition as a reason in her practical reasoning.

Another common situation in which it is appropriate to act on mere acceptance comes from scientific practices. There are cases in which the scientists' actions are based on some background assumptions that they know to be false. For example, nobody in the scientific community believes in the validity and completeness of Newton's theory of motion. But because of its convenience for making calculations in certain contexts, it is warranted for scientists to use Newton's laws as premises in their reasoning, acting as if such laws were true, at least as long as the margins of error permit it. When used in practical reasoning, these laws can provide sufficiently precise predictions given specific practical purposes. This is compatible with scientists knowing that Newtonian laws are false. ${ }^{19}$

The point can be generalized to the majority of natural laws. It is widely accepted in the scientific community that no contemporary physical theory is actually true. Science is far from having reached conclusive results. However, in practice scientists accept the available natural laws, using them as premises in at least some of their reasoning in order to calculate, design experiments and so on. Accepting natural laws in order to use them in one's reasoning is very convenient in specific circumstances: it helps in achieving reasonably accurate conclusions in a simpler and faster way, even though the scientist is well aware that these laws are false. ${ }^{20}$

A specific example could be useful here. A scientist, Mary, must deliberate about which specific act of computation she should perform in order to calculate the amount of fuel needed to get to the moon and back in a lunar module. Mary needs to calculate the amount of fuel quickly. She doesn't have time to use General Relativity, which (let's say) she actually knows to be the true theory. She can calculate the amount of fuel more quickly by using Newton's laws, which Mary believes to be false but a good approximation to the truth for her present purposes. While Mary could well use as a premise in her reasoning something she knows- e.g., the complex proposition that $[\mathrm{F}=\mathrm{ma}$ is the Newton's law necessary for calculating the needed amount of fuel, and $\mathrm{F}=\mathrm{ma}$, though false, provides a good approximation given her present practical purposes] - we can well conceive circumstances in which Mary does not use this complex proposition as a premise in her reasoning, but rather reasons as follows:

(1) I must calculate the vector sum of the force of $\mathrm{O}$.

\footnotetext{
18 Maybe such actions will cause her to believe that God exists at some future time, but before that time, most of her actions will be based on acceptance, not belief.

19 Thanks to Jonas Christensen for suggesting this case to me.

20 As a matter of fact, the use of acceptance is quite widespread in many scientific practices. See also Cohen (1992, p. 88).
} 
(2) The vector sum of the force of an object is equal to the mass multiplied by its acceleration.

(3) Therefore I shall multiply the mass of $\mathrm{O}$ by the acceleration of $\mathrm{O}$.

The use of (2) in Mary's reasoning instead of more complex propositions doesn't look rationally impermissible. Reasoning directly from the accepted Newton's law helps her in achieving the desired results in a faster and simpler way. It seems perfectly natural and reasonable to reason like this in similar circumstances. Indeed nobody would challenge reasoning (1)-(3) as inappropriate or rationally impermissible, and if Mary were asked why she drew conclusion (3), she could well cite in her defense the accepted proposition (2) instead of other known propositions. ${ }^{21}$ This example seems to be a quite realistic representation of how many scientists engaging in practical reasoning use as premises in their reasoning some accepted proposition that they believe to be false when the desired results must not be overly precise. ${ }^{22,23}$

If one were not convinced by Mary's case, here is another more familiar example from our philosophical practice. When we calculate the subjective probability of some propositions by updating evidence using Bayesian conditionalization, we know (or at least believe) that there are more precise rules for updating evidence (e.g., Jeffrey conditionalization), and thus that the proposition expressing Bayesian conditionalization is literally false. Nevertheless if we are in contexts in which we are not concerned with a high level of accuracy (for example, if we are trying to solve basic exercises

\footnotetext{
21 I am not denying here that the belief that (2) is a good approximation to a desired result plays a certain indirect role in the overall explanation, motivating and making reasonable for Mary to endorse the acceptance and use it as a premise in her reasoning. Nevertheless, in the described case Mary doesn't use the complex belief as a premise in her reasoning, but the acceptance (i.e. Newton's law). The knowledge norm is still compromised, for this norm concerns directly the attitudes that one is rational to use as premises in reasoning, not the motivations of the subject to endorse certain types of attitude and use them as premises in reasoning.
}

22 Two things are worth remarking here: the first is that acceptance of natural laws known to be false in one's reasoning is not something specific to scientific practice. Laws are directly used as premises in reasoning by, for example, engineers and teachers. The second remark is that in Mary's example I focused on a case in which it is urgent to make a decision. This should provide a further reason for Mary not to engage in complex reasoning and instead rely on acceptance. Other factors may influence the preference for acceptance over more complex beliefs. Another is, for example, the presence of multiple consecutive deliberations involving common premises-consider a variant of Mary's case in which she has to repeat the calculation several times; in such case it is simpler to rely on the accepted Newton's law than to repeatedly rely on complex beliefs and more elaborated inferential patterns.

23 An anonymous referee considers the possibility of a pragmatic explanation of the case: while in conversation Mary can express her reasoning as in (1)-(3), that may just be shorthand for a more complex reasoning understood in the conversational context, involving only beliefs as premises. Notice however that as I described the case, there is no conversational context in which Mary talks about her inference. Rather, the case involves a genuine inferential transition from premises (1) and (2) to conclusion (3). This excludes the possibility of explaining the case in terms of conversational implicatures. Another reason to think that a pragmatic account of Mary's reasoning is implausible is the following. To someone who criticizes Mary for relying on a false premise it seems to make perfect sense to answer by saying that, of course, Newton's law is false, but making as if it were true and relying on it in her reasoning makes things simpler and reaches a conclusion whose accuracy is sufficient for present practical purposes. This possible answer seems perfectly fine in this context, but it is incompatible with a pragmatic account, according to which the only correct answer to the challenge should be the resolution of a conversational implicature (for example: "of course, I was not speaking literally. What I really meant was...”). The fact that the former answer seems perfectly appropriate shows that a pragmatic account about this and similar cases is inadequate. 
in a Decision Theory course), we make as if the proposition expressing Bayesian conditionalization were true. When we reason from this proposition in such contexts, we deliberately overlook the fact that it is inaccurate and we move automatically to a conclusion, as we would do in reasoning from a belief. This way of reasoning from accepted propositions that we believe to be false (or at least we would hardly say we believe) in our philosophical practice seems to me both common and perfectly rational.

In both the exemplified cases of the Pascalian wager and the scientific practice, it seems perfectly rational for an agent to treat a proposition that is accepted but not believed as a reason for action. These cases constitute counterexamples to NEC and necessity versions of other doxastic norms.

From the case of scientific practice, we can also develop a counterexample to certain versions of SUFF. As I said in Sect. 1, while some philosophers interpret epistemic norms as concerning a specifically epistemic sense of appropriateness, others conceive appropriateness in a more liberal sense (for example as substantive rational permissibility). The example I will consider below is problematic for all those endorsing the latter interpretation of SUFF (e.g. Hawthorne and Stanley 2008). A counterexample to this version of SUFF is one in which $S$ knows that $p$, but given the setting of $S$ 's situation, it is not rationally permissible for $S$ to treat $p$ as a reason for acting. Consider again the above scenario in which Mary knows the true and complex physical law of General Relativity necessary to calculate the precise amount of fuel needed for a lunar module to get to the moon and back. We can imagine a similar situation in which it is not rationally permissible for her to take that known proposition as a premise in her reasoning. Suppose again that Mary needs to calculate the amount of fuel only to a rough approximation, but it is particularly urgent that she does that in a very short time (e.g., she has only twenty seconds to enter an estimation of the amount of fuel into the control system of a machine). ${ }^{24}$ In such a situation, since adopting Newtonian laws would perfectly suffice for the purpose, it would be unreasonable for her to use the complex law in her calculations. This is incompatible with SUFF. Note that Mary's epistemic position with respect to the proposition expressing the true physical law is also strong enough to satisfy the constraints required by other epistemic norms (justified belief that $p$, warranted belief that $p$ to a degree that is adequate relative to deliberative context, or justified belief that $S$ knows that $p$ ). And in the described situation it is inappropriate for her to use that proposition as a premise in her practical reasoning no matter how strong her epistemic position is with respect to that proposition. Therefore, all the sufficiency versions of other epistemic norms, if interpreted in the liberal sense considered above, are confronted with a problem in dealing with this type of case as well. ${ }^{25}$

\footnotetext{
24 Parameters including urgency that constitute deliberative contexts are discussed in Gerken (2011). One might worry here that though the agent in those cases seems to be blameless and fully excusable, he/she does violate some epistemic norm. I will address this possible worry in Sect. 2.3.

25 Similar cases against SUFF can be made involving other attitudes. For example, suppose that Karen knows the axioms of number theory, and that Meera, who is reliable with mathematical knowledge, said that $p$ is a theorem (although it is false). It becomes an urgent question for Karen whether $p$ is a theorem.
} 
A possible worry here could be that since acceptance doesn't involve rational commitments to the truth of the accepted proposition, acceptances are not liable to rational criticism and thus cannot serve as rationalizers of an action or a deliberation when used as premises in practical reasoning. ${ }^{26}$ However, I think that this worry is misplaced. As I said above, acceptances can be rationally assessed and criticized according to practical standards, and agents using acceptances as premises in practical reasoning are liable to rational criticism according to these standards. For example, if one concludes that accepting that God exists has the best expected utility, but then accepts that God doesn't exist and uses this acceptance as a premise in her reasoning, her acceptance can be assessed as unwarranted, and premising this proposition in her reasoning is liable to criticism. Similarly, consider the case of an engineer who accepts some law of Newton's theory in a context in which this theory doesn't provide sufficiently precise predictions for her specific practical purposes (e.g., for designing a particle collider machine), and she applies such laws as premises in her reasoning in that context (e.g., for making calculations whose results are necessary to design hadron accelerators). The reasoning of this engineer is liable to criticism and her acceptance cannot rationalize her action. This is because that acceptance is unreasonable given the practical purposes of the engineer in that context.

\subsection{Rational action performed by the skeptic}

Consider the following dialogue in which a skeptic $(K)$ is trying to convince her friend $(F)$ that she doesn't know that there is an external world.

$K$ : "Do you know that you are not a brain in a vat?"

$F$ : "No, I don't know."

$K$ : "If you are a brain in a vat, then you cannot hold this cup of coffee in your hand, because you don't have hands at all. So, since you don't know that you are not a brain in a vat, you don't know that you have a cup of coffee in your hand." After brief thought, $F$ concludes: "Yes, you are right, I don't know that." Thus she suspends her judgment. At the same time, $F$ moves her cup to her lips and drinks the coffee.

I assume that: (1) $F$ takes the conversation seriously and answers $K$ sincerely, i.e., $F$ does not give that answer to $K$ due to any non-epistemic considerations, such as social graces and reluctance to displease her friend; rather, $F$ is truly convinced by $K$ 's reasoning and suspends her judgment as a consequence of that reasoning; (2) in moving the cup $F$ genuinely exercises her agency; (3) the proposition that there is a cup of coffee in $F$ 's hand (hereafter, $\mathrm{H}$ ) is one of the reasons motivating her action; (4) The proposition that $F$ treats as a reason for lifting her hand is $\mathrm{H}$, not some complex proposition such as that, whether or not she is a BIV, seemingly lifting her hand will cause a pleasant taste and sensation of warmth.

\section{Footnote 25 continued}

It is unreasonable for her to start reasoning from the axioms - she should instead rely on Meera's testimony. Thanks to an anonymous referee for this point.

26 Thanks to an anonymous referee of this journal for directing my attention to this worry. 
Now, intuitively, it seems that $F$ 's action cannot be criticized as irrational. ${ }^{27}$ According to NEC, if it is appropriate for $F$ to treat $\mathrm{H}$ as a reason for acting, then $F$ knows H. But $F$ voluntarily suspended her belief that $\mathrm{H}$. $F$ doesn't believe $\mathrm{H}$ anymore, and consequently does not know that $\mathrm{H}$. This is a counterexample to NEC.

It might be argued that in the above example there are other beliefs (plausibly amounting to knowledge) which $F$ may be using as premises in her practical reasoning - in particular the belief that there might be a cup of coffee in front of $F$. Given the low cost of the action, this belief seems sufficient to rationalize it. ${ }^{28}$ This objection can be addressed by considering other analogous cases in which the skeptic doesn't merely suspend her judgment on the relevant proposition but believes that proposition to be false. Consider domain-relative forms of skepticism, such as skepticism about the existence of objects in the domains of mathematics, modality, ethics, etc. Such forms of skepticism are compatible with fictionalism with respect to each of these domains. For example, a fictionalist skeptic about mathematics holds that we should not believe in the existence of mathematical objects and we should regard sentences about mathematical objects, not as aiming at literal truth, but as telling part of a fictional story. For this skeptic, even if mathematical sentences are all false, engaging in a discourse about mathematics is rational because of its utility (Leng 2015). Similarly, the fictionalist can rationally act as if those sentences were true. Lacking beliefs about mathematical propositions doesn't make the use of these propositions as premises in one's reasoning irrational or unreasonable. A fictionalist mathematician can perfectly well use sentences such as ' $7+5=12$ ' or 'There are no square prime numbers' as premises in her reasoning (both theoretical and practical); she can continue doing mathematics by adopting non-doxastic attitudes towards ordinary mathematical propositions. ${ }^{29}$ In such cases, a skeptic about a certain area of discourse overtly believes that a proposition is false (and thus that it might not be true), but relies on it in her reasoning as if it were true. One can see the skeptic about the external world in my previous example as relying on an analogous sort of attitude in her practical reasoning.

One may object that $F$ still involuntarily believes that $\mathrm{H}$ even though she would not be voluntarily willing to assent to it (Pritchard 2000, p. 203). If this were the case, according to some externalist account of knowledge, $F$ would know that $\mathrm{H}$ as long as some external condition is satisfied-for instance, if $F$ 's belief that $\mathrm{H}$ were reliably formed. Furthermore, Williamson (2000) convincingly argues that knowledge is not a luminous mental state: one is not always in a position to reflectively know that she

\footnotetext{
27 Here I don't want to argue that before this conversation $F$ didn't know that there was a cup of coffee in her hand. In fact $F$ may have known that proposition before the conversation, but may have suspended her belief in that proposition as a consequence of the considerations proposed by $K$.

28 Thanks to an anonymous referee for raising this objection.

29 It has been widely argued that people who refuse to accept the truths of mathematics can still continue doing mathematics by having an attitude towards mathematical objects sometimes referred as make-believe (also acceptance or exploitation) (see e.g. Van Fraassen 1980; Yablo 2006; Daly 2008).
} 
knows something. In the light of the above observations, one could say that what $F$ lacks in the scenario is the higher-order knowledge that she knows that $p$, but not the first-order knowledge that $p$.

A possible way to defend the step from $F$ 's claimed suspension of judgment about $\mathrm{H}$ to $F$ 's ignorance of that proposition is by assuming that, even if in general knowledge may not be transparent to a subject, there are possible situations in which a subject in a case like that of $F$ has an appropriate access to her own epistemic states. The possible failure of transparency in some cases does not entail that one is always wrong about her first-order mental states. In particular, it is possible to conceive a scenario like the one described above such that, when $F$ sincerely asserts that she doesn't know that H, she has a full epistemic access to the fact that she withholds her belief that $\mathrm{H}$. In such a possible case, $F$ would thereby not know that $\mathrm{H}$. Even one single possible case like this is sufficient to provide a counterexample to NEC. ${ }^{30}$

A more powerful objection is the following. There are possible ways of interpreting what's going on in $F$ 's psychology in the above case, some of which is incompatible with the case being a counterexample to NEC. For example, Egan (2008) has recently argued for the view that the systems of belief that we in fact have are fragmented and could include subsets of beliefs which are possibly inconsistent. This view is opposed to idealized models of human cognition according to which our beliefs would be part of a single coherent system. In the above case, one can interpret $F$ 's cognitive system as fragmented, her skepticism not affecting her belief that $\mathrm{H}$. If so, $F$ can rely on the belief that $\mathrm{H}$ in her action. So described, the case wouldn't constitute a counterexample to NEC. 31

I concede that it's a much debated question in philosophy of psychology how to interpret similar cases, and that a "fragmented mind" hypothesis seems a possible way of interpreting what's going on in $F$ 's psychology in the above example. I admit that there are several possible interpretations of the case, some of which incompatible with the case being a counterexample to NEC. But remember here that in order to make my point, all that I need is that there be at least one psychologically possible description of the example (or similar examples) under which $F$ doesn't believe that $\mathrm{H}$. The possibility of a single case in which $F$ doesn't believe that $H$ would be already a counterexample to NEC. This is perfectly compatible with there being other descriptions of this and similar cases according to which the subject believes the relevant proposition (as in the "fragmented mind" interpretation). However, in the present context I cannot settle the issue of whether a description of the case that suits my purposes is psychologically possible. For this reason, I will set this issue aside and for the sake of argument I will simply assume that a similar description is indeed possible. My conclusion about the present case will thus be merely conditional: assuming an inter-

\footnotetext{
30 Neta (2009) argues that it is possible to know that $p$ even if one believes that one does not know that $p$. But Neta's point doesn't conflict with what is suggested here.

31 I thank an anonymous referee for pointing out the need to address this objection.
} 
pretation of this (or some similar) case as one in which the subject doesn't believe the target proposition, the case constitutes a counterexample to NEC. ${ }^{32}$

\subsection{A reply to a possible objection}

One could defend the knowledge norm by arguing that though the agent in those cases seems to be blameless, he/she does violate the knowledge norm. Hawthorne and Stanley consider a situation in which someone in a situation of urgency is intuitively blameless in acting on mere partial belief. They claim that this kind of case doesn't ultimately threaten the knowledge norm; according to them, "the fact that we do not blame someone forced into a quick decision is no evidence at all against it" (Hawthorne and Stanley 2008, p. 587). In their view, the agent is blameless because the practical circumstances excuse her for violating the knowledge norm. Similarly, Hawthorne and Stanley could object to the above counterexamples by saying that the agent violates the norm but is excusable, for in these situations practical considerations render it excusable to act on less than knowledge.

Here are two replies. First, in the exemplified cases it is hard to see in what sense the agent needs to be excused. Our intuition suggests that the agent does not violate any epistemic constraint on practical rationality. For instance, when scientists have good reasons to use an out-of-date Newtonian law as a premise in their calculation, we neither judge them as acting inappropriately in any sense nor do we feel them in need of excuse for some wrongdoing. In these cases, there is no indication of the violation of some normative standard, either practical or epistemic: no criticizability, no blameability or excusability according to any normative assessment whatsoever.

Second, the maneuver of appealing to excuses is rather unpromising. Gerken (2011) points out that unless upholders of the knowledge norm can specify the notions of excuse and/or blamelessness, an appeal to excuses would be ad hoc and thus unconvincing. He then critically considers several possible principled accounts of excuse, and argues that none of them is free from serious problems. It seems even more implausible to work out a viable account of excuse able to accommodate the types of cases

\footnotetext{
32 What could be the mental attitude that $F$ has towards $\mathrm{H}$ if it is not belief? There are two possible interpretations here. One is acceptance: $F$ decides to adopt the working hypothesis that she is not massively deceived in order to simplify her thinking, and uses this hypothesis as a premise in her reasoning. Alternatively, we can conceive the example as one in which $F$ relies on $\mathrm{H}$ in an unreflective way, without first explicitly performing an act of acceptance. In this case, interpreting the attitude as acceptance would probably not be very accurate. A wide literature on Pyrrhonism suggests that the relevant attitude in such a case would be appearance. Sextus Empiricus (1994) describes an appearance as an involuntary affection (pathos) of the skeptic, something she passively undergoes. Unlike belief, an appearance makes no claims regarding the truth-value of $p$. Appearances, unlike beliefs, do not aim at truth, in the sense that they are not attitudes directed at correctly representing real states of affairs. Accordingly, they cannot be questioned and criticized with regard to their truth-dimension. Rather, they are appropriately assessed with regard to promoting a life free from turmoil and favoring the achievement of imperturbability. While beliefs involve a commitment to the truth of what is believed, appearances are attitudes supposed to represent with the practical aim of acquiring peace of mind.
} 
considered above, not to mention that each of them involves completely different sorts of circumstances. ${ }^{33}$

\section{Conclusion}

What conditions make it appropriate to treat $p$ as a reason for action? In this paper, I argued that neither knowing that $p$ nor believing that $p$ are necessary or sufficient conditions for appropriately treating $p$ as a reason for action. Notice however that the aim of this paper was not to criticize RKP and other doxastic norms of practical reasoning on the ground that knowledge or warranted belief don't play any role for the rationalization of actions. Rather, it was to point out the limits of these principles by showing how rational actions may be based in some cases on other mental attitude such as acceptance.

Acknowledgements I would like to thank audience at the Xmas Epistemology Fest (University of Edinburgh, 2012), the Graduate Conference in Theoretical Philosophy (University of Groningen, 2013), and the 87th Joint Session of the Aristotelian Society \& Mind (University of Exeter, 2013). I would also like to thank Mikkel Gerken, Allan Hazlett, Duncan Pritchard and five anonymous referees from Synthese for their invaluable comments on earlier drafts. A special thank goes to Davide Fassio for his considerable feedbacks and support. I benefited from the China Scholarship Council/University of Edinburgh Scholarship and a Jacobsen Studentship.

Open Access This article is distributed under the terms of the Creative Commons Attribution 4.0 International License (http://creativecommons.org/licenses/by/4.0/), which permits unrestricted use, distribution, and reproduction in any medium, provided you give appropriate credit to the original author(s) and the source, provide a link to the Creative Commons license, and indicate if changes were made.

\section{References}

Alston, W. (1996). Belief, acceptance, and religious faith. In D. Howard-Snyder \& J. Jordan (Eds.), Faith, freedom, and rationality (pp. 3-27). London: Rowman \& Littlefield.

Audi, R. (2008). Belief, faith, and acceptance. International Journal for Philosophy of Religion, 63(1/3), 87-102.

Benton, M. A. (2014). Knowledge norms. Internet Encyclopedia of Philosophy. Accessed October 4, 2015, from http://www.iep.utm.edu/kn-norms/.

Bratman, M. (1992). Practical reasoning and acceptance in a context. Mind, 101(401), 1-16.

Broome, J. (2013). Rationality through reasoning. Oxford: Wiley-Blackwell.

Brown, J. (2008a). Knowledge and practical reason. Philosophy Compass, 3(6), 1135-1152.

Brown, J. (2008b). Subject-sensitive invariantism and the knowledge norm for practical reasoning. Noûs, 42(2), 167-189.

Brown, J. (2012). Assertion and practical reasoning: Common or divergent epistemic standards? Philosophy and Phenomenological Research, 84(1), 123-157.

Buckareff, A. A. (2004). Acceptance and deciding to believe. Journal of Philosophical Research, 29, 173190.

Cohen, J. (1989). Belief and acceptance. Mind, 98(391), 367-389.

\footnotetext{
33 Note that it seems to be even more implausible for upholders of the doxastic norms to use the excuse maneuver for defending their views. Those philosophers reject the excuse maneuver made by proponents of the knowledge norm. That would require developing a notion of excuse that could handle the cases of acceptance and appearance but maintain that there is no need of excuse in cases like the urgency situation considered by Hawthorne and Stanley.
} 
Cohen, J. (1992). An essay on belief and acceptance. New York: Clarendon Press.

Daly, C. J. (2008). Fictionalism and the attitudes. Philosophical Studies, 139(3), 423-440.

Dennett, D. (1978). How to change your mind. Mongtomery, VT: D. Dennett, Brainstorms, Bradford Books Publishers Inc,

de Sousa, R. B. (1971). How to give a piece of your mind: Or, the logic of belief and assent. Review of Metaphysics, 25(1), 52-79.

Dub, R. (2015). Delusions, acceptances, and cognitive feelings. Philosophy and Phenomenological Research, 91(3), 723-759.

Egan, A. (2008). Seeing and believing: Perception, belief formation and the divided mind. Philosophical Studies, 140(1), 47-63.

Engel, P. (1998). Believing, holding true, and accepting. Philosophical Explorations, 1(2), 140-151.

Engel, P. (2013). Doxastic correctness. Aristotelian Society Supplementary, 87(1), 199-216.

Fantl, J., \& McGrath, M. (2002). Evidence, pragmatics, and justification. Philosophical Review, 111(1), 67-94.

Fantl, J., \& McGrath, M. (2007). On pragmatic encroachment in epistemology. Philosophy and Phenomenological Research, 75(3), 558-589.

Fantl, J., \& McGrath, M. (2009). Knowledge in an uncertain world. Oxford: Oxford University Press.

Frankish, K. (2004). Mind and supermind. Cambridge: Cambridge University Press.

Gerken, M. (2011). Warrant and action. Synthese, 178(3), 529-547.

Gerken, M. (2015). The role of knowledge ascription in epistemic assessment. European Journal of Philosophy, 23(1), 141-161.

Hawthorne, J. (2004). Knowledge and lotteries. Oxford: Oxford University Press.

Hawthorne, J., \& Stanley, J. (2008). Knowledge and action. Journal of Philosophy, 105(10), 571-590.

Leng, M. (2015). Fictionalism in the philosophy of mathematics. In Internet Encyclopedia of Philosophy. Accessed November 16, 2015, from http://www.iep.utm.edu/mathfict/.

Littlejohn, C. (2009). Must we act only on what we know? Journal of Philosophy, 106(8), 463-473.

Littlejohn, C. (2012). Justification and the truth-connection. Cambridge: Cambridge University Press.

Littlejohn, C. (2013). The russellian reteat. Proceedings of the Aristotelian Society, 113(3pt3), 293-320.

Maher, P. (1990). Acceptance without belief. PSA: Proceedings of the Biennial Meeting of the Philosophy of Science Association, 1990, 381-392.

McHugh, C., \& Whiting, D. (2014). The normativity of belief. Analysis, 74(4), 698-713.

Mosterín, J. (2002). Acceptance without belief. Manuscrito, 25(2), 313-335.

Neta, R. (2009). Treating something as a reason for action. Noûs, 43(4), 684-699.

Pritchard, D. (2000). Doubt undogmatized: Pyrrhonian scepticism, epistemological externalism, and the "metaepistemological" challenge. Principia-Revista Internacional de Epistemologia, 4, 187-214.

Rey, G. (1988). Toward a computational account of akrasia and self-deception. In B. McLaughlin \& O. Rorty (Eds.), Perspectives on self-deception (pp. 264-296). London: University of California Press.

Rey, G. (2007). Meta-atheism: Religious avowal as self-deception. In Antony (Ed.), Philosophers without gods: Meditations on atheism and the secular life (pp. 243-265). Oxford: Oxford University Press.

Sextus Empiricus. (1994). Outlines of Pyrrhonism. (Annas \& Barnes, Trans.).

Shah, N. (2003). How truth governs belief. Philosophical Review, 112(4), 447-482.

Sperber, D. (1996). Explaining culture: A naturalistic approach. Oxford: Basil Blackwell.

Sperber, D. (1997). Intuitive and reflective beliefs. Mind and Language, 12(1), 67-83.

Stalnaker, R. (1984). Inquiry. Cambridge, MA: MIT Press.

Stanley, J. (2005). Knowledge and practical interests. Oxford: Oxford University Press.

Steglich-Petersen, A. (2006). No norm needed: On the aim of belief. Philosophical Quarterly, 56(225), 499-516.

Tuomela, R. (2000). Belief versus acceptance. Philosophical Explorations, 3(2), 122-137.

Vahid, H. (2006). Aiming at truth: Doxastic versus epistemic goals. Philosophical Studies, 131(2), 303-335.

Van Fraassen, B. C. (1980). The scientific image. Oxford: Oxford University Press.

Van Leeuwen, N. (2014). Religious credence is not factual belief. Cognition, 133(3), 698-715.

Velleman, D. (2000). On the aim of belief. In G. Cullity \& B. Gaut (Eds.), The possibility of practical reason (pp. 244-281). Oxford: Oxford University Press.

Wedgwood, R. (2002). The aim of belief. Philosophical Perspectives, 16(s16), 267-297.

Wedgwood, R. (2013). Doxastic correctness. Aristotelian Society Supplementary, 87(1), 217-234.

Williamson, T. (2000). Knowledge and its limits. Oxford: Oxford University Press. 
Wright, C. (2004). Warrant for nothing (and foundations for free)? Proceedings of the Aristotelian Society, Supplementary Volumes, 78, 167-212.

Yablo, S. (2006). Non-catastrophic presupposition failure. In J. J. Thomson \& A. Byrne (Eds.), Content and modality: Themes From the philosophy of Robert Stalnaker. Oxford: Oxford University Press. 